This is the author's final, peer-reviewed manuscript as accepted for publication. The publisher-formatted version may be available through the publisher's web site or your institution's library.

\title{
Workplace hostility: defining and measuring the occurrence of hostility in the workforce
}

Meridith Pease Selden, Ronald G. Downey

\section{How to cite this manuscript}

If you make reference to this version of the manuscript, use the following information:

Selden, M. P., \& Downey, R. G. (2012). Workplace hostility: Defining and measuring the occurrence of hostility in the workforce. Retrieved from http://krex.ksu.edu

\section{Published Version Information}

Citation: Selden, M. P., \& Downey, R. G. (2012). Workplace hostility: Defining and measuring the occurrence of hostility in the workforce. Work: A Journal of Prevention, Assessment and Rehabilitation, 42(1), 93-105.

Copyright: @ IOS Press.

Digital Object Identifier (DOI): doi:10.3233/WOR-2012-1332

Publisher's Link:

http://iospress. metapress.com/content/21471956654856lx/?p=4e59d81c0ab740a6825c8 d60b211e246\&pi $=12$ 
Workplace Hostility: Defining and Measuring the Occurrence of Hostility in the Workforce

\begin{abstract}
Objectives: The purpose of this study was to define a comprehensive construct, workplace hostility, encompassing sub-areas of harmful workplace behaviors. Key characteristics include: perception of the target, persistence, intentionality, nonphysical nature, and organizational affiliation.

Participants: Pilot study participants ( $\mathrm{N}=42$, students and $\mathrm{N}=35$, workers) were small convenience samples. Main study participants ( $\mathrm{N}=393,70 \%$ female) were working individuals and almost 50\% reported 1 to 5 years in their current jobs.
\end{abstract}

Methods: The two pilot studies collected surveys face-to-face. The main study used online surveys.

Results: Based on the pilot studies, items from the Workplace Hostility Inventory (WHI) were judged as a reasonable set. Results from the main study suggested three subscales related to perceptions of being subjected to hostility: interference with work, denigration, and exclusion. Supervisors produced greater distress on all factors, but only exclusion predicted a desire to leave the organization. Distress was greater when the perpetrator was a woman or a group. After controlling for feelings toward coworkers and supervisors, WHI was not related to job satisfaction.

Conclusions: The WHI was found to be an inclusive construct, representing numerous concepts. The WHI is comprehensive and global, encompassing the previous overlap in existing research.

Keywords: Abuse, Job Satisfaction, Job Violence, Toxic Behavior 
Workplace Hostility: Defining and Measuring the Occurrence of Hostility in the Workforce

\section{Introduction}

In recent years, there has been an increased focus on the examination of harmful workplace behaviors [1] [2] [3]. Harmful workplace behavior is a broad field that includes numerous sub-areas (see Table 1). Research has "found duplication of effort both conceptually and empirically" (p. 32) for these sub-areas that can be attributed to the simultaneous development of similar perspectives [4]. The contextual features used to measure each construct, serve to differentiate between similar behaviors limiting the utility of each. This has been acknowledged as a shortcoming by researchers [4] [3]. Although a fragmented field, four common contextual features have been identified in the literature as: ability to cause harm, the target's desire to avoid the treatment, intent of the perpetrator to cause harm, and the persistent nature of the treatment [3].

The purpose of this study is to define a construct that encompasses the majority of the behaviors within the harmful workplace behavior field and to develop a comprehensive scale. The new construct will encompass the four common contextual features of harmful workplace behaviors [3]. As with all of the constructs in this field, workplace hostility includes behaviors that can cause harm to the target and thereby the target is motivated to avoid. However, workplace hostility only includes unambiguous episodes of hostility that occur repeatedly at the hands of the same person or group of people. The key characteristics of workplace hostility meriting further examination are as follows: perception of the target, persistence, free will, nonphysical nature, and organizational affiliation. These are briefly explored below. 
Perception of the Target - The perceived intent of the perpetrator is more important than the actual intent, thus individuals must perceive that they were targets of mistreatment. If this condition is not met, then regardless of the intent of the perpetrator, workplace hostility has not occurred. This characteristic is similar to the requirements of abusive supervision [5] [6], which is based entirely on the subordinates' perceptions. This subjective assessment is also present in the EEOC [7] definition of sexual harassment.

Persistence - It is necessary to have repeated poor treatment at the hands of the same perpetrator and/or same group of perpetrators, although the behaviors may differ. More specifically, the behaviors must be persistent enough to create a pattern of mistreatment.

Free Will - Behaviors must be a purposeful act voluntarily undertaken by the perpetrator. If a behavior is explicitly mandated by an organization and carried out by a person acting as representative of an organization (e.g., a supervisor) then it is not workplace hostility. An example would be restrictions on breaks. Also, if a behavior occurs as a result of an obvious accident (e.g., printer malfunction) then it is not workplace hostility, regardless of the impact the behavior has on the target.

Non-Physical Nature - Only behaviors that do not involve physical violence are classified as workplace hostility. The decision to exclude physical behaviors limits the workplace hostility construct but does so constructively. Physical violence happens relatively rarely but receives a large amount of press and research coverage [8]. More specifically, physical assault has been found to occur in one out of every 25 acts of bullying while verbal abuse occurred in one out of every 4 acts of bullying (United States 
Postal Serv. as cited in [9]). Additionally, there are precedents to exclude physical behaviors [5] [6].

Organizational Affiliation - If a behavior occurs between two individuals from different organizations (e.g., verbal abuse by a customer), it is not considered workplace hostility. This limitation is necessary so as to exclude hostility that is not work related. Additionally, the nature of the relationship between the two employees of the same organization is inconsequential in defining workplace hostility, with employees at any level being susceptible to experiencing it. There are precedents for including only work related hostility [10] [11] and for not limiting the susceptibility of hostility to only one level within the organization [11].

The above criteria establish the basic conditions that need to be met for workplace hostility (WH). The goal now is to develop, define, and measure harmful workplace behaviors that meet the criteria. The measurement instrument being developed and used in the current study is called the Workplace Hostility Inventory (WHI). To combat the fragmentation within the field and to test if the existing measures truly are different measures, the WHI was developed from a combination of existing concepts and items. Seven measures were selected due to their prominence in the literature and relevance to Workplace Hostility. See Table 1 for a list of current constructs within the field. All of the measures were modified to fit into the WHI. The behaviors (i.e., "Gave me the silent treatment") were largely unaltered but the questions asked about the behaviors were changed, all identifiable characters (i.e., "My boss") were removed, more than one perpetrator was allowed, a clear target was indicated, and a new response scale was used. Permission was obtained from all but one author 
of these scales ${ }^{1}$ to use and modify their items. Each of the measures will be explored below. Due to construct overlap, some items were attributed to more than one scale. Workplace Aggression [12] - The WAR-Q is a common and large item assessment of workplace aggression. However, it does not differentiate between acts experienced at the hands of the same person or of many different people. Of the 39 items in the $\mathrm{WHI}, 20$ can be attributed to the WAR-Q, although they were modified to allow more than one perpetrator and to indicate the target. Because the WAR-Q is a commonly used and large scale, items were selected from the WAR-Q that can also be attributed to other scales. For example "Gave the silent treatment" can be attributed to the WAR-Q, Social Undermining [13], and Abusive Supervision [5] [6]. Therefore although 20 items can be attributed to the WAR-Q most of these items can also be attributed to another source.

Abusive Supervision [5] [6] - Abusive supervision involves subjective judgment and sustained activity, not including physical contact. Six of the items from the Abusive Supervision scale are included in the WHI.

Workplace Deviance [14] [15] - Workplace Deviance defines employee deviance as voluntary behaviors that violate organizational norms. After significant revision to shift the perspective, three items were included in the WHI.

Social Undermining [13] - Social undermining is a series of work related behaviors designed to hinder the target's ability to maintain a positive standing within

\footnotetext{
${ }_{1}^{1}$ One of the scale authors failed to respond to any of the numerous attempts to contact him or identify alternative addresses. Fewer than five items were adapted from this scale and they were significantly revised.
} 
his/her work environment. Four items from the Social Undermining Scale were included in the $\mathrm{WHI}$.

Workplace Incivility [16] - Incivility is a low intensity behavior with ambiguous intent. However, it is often viewed as somewhat immoral, connoting breaches of both personal and professional etiquette [17]. Two items were included in the WHI.

Perceptions of Fair Interpersonal Treatment, PFIT [18] - The PFIT is a broad scale assessing supervisor treatment and coworker treatment. After modification to reflect the focus, four items were included.

Negative Social Exchange, TENSE [19] - The TENSE was designed to assess potential negative interpersonal interactions. After modification for perspective, three items from TENSE were included in the WHI.

Thus, thirty-nine items were incorporated into the preliminary WHI survey. The preliminary survey was evaluated to determine the adequacy of developed items to effectively gather information related to the key characteristics that make it a unique construct. Further, the WHI examined how each characteristic relates to areas previously proven to have an effect on an employee's perceptions and beliefs regarding themselves or their company after experiencing harmful workplace behaviors.

Since workplace hostility was created to encompass behaviors within the harmful workplace behavior, it is necessary to first test if the items on the WHI represent one factor (i.e., harmful behaviors). If the WHI is not one factor and therefore has an underlying factor structure of two or more factors, an exploratory factor analysis to identify subscales will be conducted. The first hypothesis is as follows:

Hypothesis 1: Workplace hostility represents one factor. 
Research has shown that abuse by supervisors occurred more frequently than abuse by coworkers and the negative effect of the abuse was worse when enacted by supervisors versus coworkers [5] [6] [13] [12]. Therefore, it is expected that the workplace hostility will occur more often from people in positions of power and this power dynamic will result in greater levels of upset. The following hypotheses were formulated:

Hypothesis 2: Workplace hostility occurs from people in positions of power (i.e., supervisors) more frequently when compared to those with less power (i.e., coworkers or subordinates).

Hypothesis 2a: When the perpetrator is in a position of power (i.e., supervisor) over the target, the target will express more distress than when the perpetrator is not in a position of power (i.e., coworker or subordinate) over the target.

Previous research has found the effects of aggression to be cumulative, with participants reporting higher stress levels when bullied by multiple actors, and numerous people bullying a target is viewed as worse than a lone bully [11]. Thus the following hypothesis was generated:

Hypothesis 3: Workplace hostility that occurs at the hands of multiple individuals (i.e., a group) will be perceived as more upsetting than workplace hostility that occurs at the hands of a lone perpetrator.

Finally, a preliminary exploratory model will be examined. This model will be created using the workplace hostility subscales while controlling for other situational variables, including job clarity, measures related to the participants' feelings about their coworkers and supervisors, and the number of perpetrators, to predict the criterion 
variable of job satisfaction. Understanding the ramifications of workplace hostility is hypothesized to be an important component in predicting work related outcomes. It is important to ensure that the workplace hostility subscales contribute to the prediction thereby extending our understanding beyond variables that are already known to be predictors of work outcomes. The final hypothesis is as follows:

Hypothesis 4: Subscales of the WHI will predict job satisfaction above and beyond control factors.

The hypotheses were tested using data collected at three points in time from three samples. The first two data collections ("Norm Study" and "Instrument Study") were pilot studies used to refine the measurement instrument. The final data collection, the "Main Study" occurred after changes were made to the instrument based on the results of the pilot studies. Each study will be reported separately.

\section{Norm Pilot Study}

Implicit in the definition of workplace hostility is the idea that the hostile behaviors violate organizational or social norms. The purpose of the norm pilot study was to ensure that all of the $\mathrm{WHI}$ behaviors violated either an organizational or a social norm.

\section{2a. Method}

Forty-two participants from three different locations (a community college, a state school, and a non-profit organization) participated in the norm pilot study. The mean age of the participants in the three locations was $26.55(\mathrm{SD}=11.91)$ with a range of 18 to 60. Testing was conducted to determine if the three samples were similar enough to combine into one larger sample. Namely, two one-way ANOVAs treating the locations as independent variables (i.e., 1, 2, or 3) and composite "violation" scores (i.e., social 
and organizational) of the 39 behaviors as the dependent variable were conducted. For both types of norms, the group composite ratings were similar, $F(2,39)=.118, p=.89$ for social and $F(2,39)=.478, p=.62$ for organizational. Thus, the groups were combined.

All forty-two participants were asked to complete a survey indicating whether they believed each of the $39 \mathrm{WHI}$ behaviors was a violation of a social norm and/or an organizational norm. Participants were also asked basic demographic questions.

\section{2b. Results and Discussion}

It had been decided that a behavior would be viewed as a violation of a social and/or organizational norm if at least half of the respondents indicated it was a violation. Since norms are by definition decided by the expectations of the majority, $50 \%$ was selected as a reasonable representation of what the majority expects. Thirty-four of the thirty-nine behaviors were found to be violations of both norms, thirty-eight behaviors violated organizational norms and thirty-five behaviors violated social norms. All thirtynine behaviors violated at least one norm and most violated both. Thus, all of the behaviors were deemed appropriate for the instrument pilot study.

\section{Instrument Pilot Study}

The purpose of the instrument pilot survey was twofold. Since very little attention has been paid to whether participants felt the behaviors were damaging, the survey first assessed whether respondents felt as if they were victims of an intentionally damaging act. Second, if a behavior was reported as occurring infrequently in the instrument pilot survey it would be excluded from the main survey.

\section{3a. Method}


The instrument pilot study was conducted at a small non-profit organization in the Eastern United States and data were collected at an all-hands meeting/retreat $(\mathrm{N}=35)$. Every employee in the organization participated in the pilot study. The participants ranged from the Executive Director to staff electricians and cooks. Employees were told that participation was voluntary and were offered chances to win gift certificates.

Because the responses might contain incriminating data, participants were ensured anonymity and told that nothing would be reported to company leaders. The survey contained the thirty-nine hostile behaviors. Participants were asked if they had been victims for each of the thirty-nine behaviors. If they said yes to any item, they were then asked to answer two additional questions about the behaviors: How upset were you when the event occurred? and Was there intent to harm?

\section{3b. Results and Discussion.}

To make decisions regarding whether people were experiencing the behaviors included on the survey, were upset at experiencing the behaviors, and the perceived intent descriptive statistics were used. The first issue examined in the instrument study was whether people were experiencing the behaviors included on the survey. While more than $90 \%(N=32)$ indicated they had experienced workplace hostility, it was important to determine if people experienced the specific WHI behaviors. The frequency of "yeses" for each behavior ranged from only $3(9 \%)$ to 29 (91\%). Nineteen of the 39 behaviors were experienced by more than half of the respondents. Not only did people experience general hostility but they also experienced the specific behaviors.

Participants were also asked to indicate how upset they were when the behavior occurred and the perceived intent of the behavior. Only participants experiencing a 
behavior were asked to respond to these two questions. All of the behaviors were viewed as at least somewhat upsetting by those who experienced them with the lowest average upset level being 2.71 on a 1 (Not at all Upset) to 5 (Very Upset) Likert-type item. Twenty-one (54\%) of the behaviors received an average score of 4 or higher. With regards to the perceived intent, ratings ranged from $13 \%$ to $94 \%$ of respondents perceiving the behavior as harmful, $M=53 \%(S D=18.0 \%)$. All behaviors were perceived as harmful by at least one person with, on average, more than half of the people reported the intent to cause harm.

The instrument pilot study included an open-ended question asking the participants to list any behaviors that he/she thought might be missing from the WHI. The few participants completing this section all listed physical aggressive behaviors, which were specifically excluded.

Based on the examination of the issues discussed above, all 39 items were included in the main study. Furthermore, when given the opportunity to list any behaviors that should have been included, participants failed to provide any useful contributions.

\section{Main Study}

Based on the results from the first two studies, the WHI was judged to be a reasonable and comprehensive measure of workplace hostility. All thirty-nine behaviors included in the main study: 1) violated either social or organizational norms; 2) were experienced by most people; 3) were perceived as harmful by most people; and 4) were reported as having a harmful intent.

\section{4a. Method}


The Internet based sample data collection procedures used here are an established method within the field of workplace bullying [20] [21] [22] [23]. The research conducted by Namie and his colleagues as well as research outside of workplace bullying found that an Internet based sample compared favorably to a conventional sample [24]. Further, it has been found that the survey administration method had little practical impact on workplace data [25].

The data for the main study was collected from an anonymous and confidential online survey posted at workplacehostility.org. Participants were not sought through any official channels, instead website and survey information was spread by word of mouth and could be located through a variety of search engines. The first page of the website contained the information about the survey and asked people to participate if they were a victim of non-physical hostility at work. Confidentiality was promised and provided. The main survey was identical to the survey used in the instrument pilot study with the exception of the outcome measures.

There were 401 volunteer respondents, of these 393 participants provided complete and consistent information. The survey was online for approximately 3 weeks. The sample was not a random sample. As discussed above, there is a precedent within the workplace aggression field for this type of data collection [20] [21] [22] [23]. In order to have reliable correlation coefficients and to be able to interpret factors with relatively low loadings (e.g., .3), a sample size of at least 300 participants is required [26] [27]. As such, the decision to stop the data collection was driven by the adequacy of the sample size and a sharp decline in the number eligible participants who visited the website. 
To examine the hypotheses, the following analyses will be conducted. For hypothesis 1, a Confirmatory Factor Analysis will be conducted to assess the validity of one factor. If there is more than one factor in the underlying structure, an Exploratory Factor Analysis will be conducted. Hypothesis 2 will be examined using a goodness of fit chi-square. While hypothesis $2 a$ and hypothesis 3 will be examined using a MANOVA where interference with work, exclusion, and denigration will be the dependent variables. Hypothesis 4 will be evaluated by conducting hierarchical regressions with the scales as predictors.

\section{4b. Main Study Results}

Thirty percent (118) of the respondents were men and 70\% (or 275) women. Since the survey was open to anyone and was not designed to specifically attract females, the discrepancy between the number of women and men respondents is interesting. Such a large difference in the number of women and men lends validity to the idea that gender differences in workplace experiences needs further exploration. However, the discrepancy is inline with previous research that indicates that women make up $80 \%$ of those who are bullied [9].

The sample was composed of a relatively experienced group of working individuals, with almost $30 \%$ of the sample $(\mathrm{N}=114)$ reported being in the workforce for more than 20 years, while less than $2 \%(\mathrm{~N}=7)$ reported being in the workforce for less than 1 year. When participants were asked to report their tenure in their current job, almost $50 \%(\mathrm{~N}=187)$ reported 1 to 5 years.

One hundred and forty (36\%) respondents indicated they felt mistreated in their current job. Of those reporting current mistreatment, $40 \%(\mathrm{~N}=56)$ indicated also being 
mistreated at previous jobs. For the entire sample, more than 50\% ( $\mathrm{N}=198)$ indicated being mistreated at a previous job. When asked if they had ever experienced workplace hostility, 309 of the 393 participants responded affirmatively. When looking only at those who reported experiencing hostile behaviors, 34 (11\% of the 309 above) reported that they had not been mistreated at a previous or current job. Thus, it is possible that some people feel hostile behavior is such a normal part of their workday that they no longer consider it mistreatment or do not view hostile behaviors and mistreatment as the same. Despite a large number of respondents indicating that they had been mistreated at work, 266 or $68 \%$ of the entire sample said "Yes" when asked if they liked their current job. The seeming disconnect between mistreatment and feelings about jobs will be further explored later.

To examine the validity of using one factor model, a Confirmatory Factor Analysis (CFA) was conducted on the basis of the upset score ("How upset were you when the event occurred?") for each behavior. Prior to running the analysis, behaviors were excluded in which fewer than $30 \%$ of sample reported experiencing the behavior. Using this criterion, ten questions were excluded. Additionally, any participant who did not experience the behavior was assigned a value of one indicating that there was no level of upset associated with a particular behavior. Answers to the upset scores were adjusted upward to reflect this coding (1=Not at all Upset to 6=Very upset).

The CFA indicated poor model fit, $\chi^{2}(435)=10687.99, \mathrm{RMSEA}=.11, \mathrm{CFI}=.89$ and suggesting that there was more than one factor involved. Therefore, an Exploratory Factor Analysis was conducted using Principal Axis Factoring (PAF) with Promax (oblique) rotation because it was expected that the factors identified would be 
correlated. The pattern matrix indicated that there were three clear factors. This was reinforced by eigenvalues greater than one on the three factors and by examining the scree plot, which indicated a clear drop off and a gradual leveling after the third factor. An item needed a loading of .3 or better to be included in a subscale. If an item was cross-loaded it was included only in the scale with the highest loading. Six items were cross-loaded. See Table 2 for the pattern matrix.

The first subscale, interference with work, included a variety of behaviors ranging from active betrayal (i.e., lying) to more passive actions (i.e., did not defend you when others spoke poorly of you) and the coefficient alpha reliability was .86. All the individual behaviors encompassed activities perceived to substantially reduce the abilities of individuals to effectively perform or be seen as performing their jobs.

The second subscale, exclusion, included two types of behaviors, ostracism and belittling, both of which resulted in exclusion. The exclusion subscale had a coefficient alpha reliability of .85 . When looked at together, all of the acts included in the exclusion scale had the same goal of exclusion, either by purposely failing to include or by belittling to the point of exclusion from normal work or social activities.

The third subscale, denigration, included five clearly denigrating behaviors. The subscale included items such as ridicule, derogatory name calling, laughed in your face, and swore at you. The denigration subscale had a coefficient alpha reliability of .76. When looked at together, the behaviors definitely had the common goal of denigration.

The three factors identified in the EFA did not map onto the various scales used to develop the WHI. One possible outcome could have been that the analysis would create subscales that closely align with the original scales, this was not the case. 
Instead, the EFA identified three scales that have not previously been identified and are a significant new finding in the field. It was further hypothesized that the three subscales would be related. The correlations between the subscales ranged from .59 to .75 . The averaged items scores for three factors will be used in following analyses.

To further explore hypothesis 1 , regression analyses were conducted where interference with work, exclusion, and denigration were the predictors and "Have you been subject to hostile behaviors at work?" ( $1=\mathrm{Yes}, 2=\mathrm{No}$, and $3=\mathrm{NA}$ ) was the criterion. The overall model significantly predicted the occurrence of hostility in the workplace, $R^{2}$ $=.43, F(3,387)=97.97, p=00$. An examination of the regression coefficients indicates that two of the factors, interference with work and exclusion, significantly contributed to the model, $\beta=.21, t(387)=3.61, p=.00$ and $\beta=.45, t(387)=6.94, p=.00$ respectively. While denigration did not contribute to the overall prediction, it had a significant zero order correlation with workplace hostility.

Thus hypothesis 1 was not supported. The underlying factor structure consisted of more than one factor. However, examining the three subscales identified in the EFA at the zero order level and in the regression analysis indicates that all three scales were positively related to workplace hostility with both interference with work and exclusion providing independent prediction of workplace hostility. The more upset people were with behaviors related to exclusion and, to a somewhat lesser extent, the more people were upset at behaviors related to work interference, the more likely they were to indicate they were victims of workplace hostility.

Hypothesis 2 predicted that workplace hostility is likely to occur from people in positions of power (i.e., supervisors) and hypothesis 2a predicted that this power 
differential between the targets and perpetrators would lead to high levels of distress. These hypotheses were examined using a goodness of fit chi-square and a MANOVA where interference with work, exclusion, and denigration were the dependent variables and the perpetrator's position relative to the target's position within the organization was the independent variable. Only 16 participants (5\%) reported that the perpetrator was a subordinate, so the independent variable was recoded to look at three groups, nonsupervisory $(N=123)$, supervisory $(N=133)$, and mixed perpetrators $(N=53)$. A significant chi-square indicated the difference in perpetrators could not be attributed to chance, $\chi^{2}(2)=36.89, p=.00$. The results of the MANOVA (see Table 3 ) indicated that the perpetrator's level within the organization significantly affected the combined dependent variable of the WHI subscales. All three subscales were found to be significant in differentiating between the levels of the perpetrators. A discriminant function analysis (DFA) was performed to clarify the results of the MANOVA and yielded one significant function (see Table 4) containing all three perpetrator levels, with $10.39 \%$ of the function variability explained. Standardized function coefficients and correlation coefficients (see Table 4) revealed that interference was the scale most associated with the function. The average amount of distress (interference and to some degree exclusion and denigration) experienced by a person abused by a supervisor was greater than the average amount of distress experienced by a person abused by either a coworker or by a mixed group. Both Hypothesis 2 and hypothesis 2 a were fully supported. Previous research found that social undermining and aggression had a more pronounced negative effect when they occurred at the hands of a supervisor than when it occurred at the hands of a coworker [12] [13]. The current study supported this finding. 
To examine hypothesis 3 the effects of multiple perpetrators when compared to a lone perpetrator, a MANOVA was conducted where the number of perpetrators (one versus more than one) was the independent variable and the WHI subscale scores were the dependent variable. The results of the MANOVA (see Table 3) indicated that the number of perpetrators significantly affected the combined dependent variable of the WHI subscales. A DFA was performed to clarify the results of the MANOVA. This analysis generated one significant function (see Table 4) containing both perpetrator levels, with $14.29 \%$ of the variance explained. Standardized function coefficients and correlation coefficients (see Table 4) revealed that interference was the scale most associated with the function. The average amount of distress experienced by a person who was abused at the hands of a group of people was more than the average amount of distress experienced by a person who was abused by only one person.

Hypothesis 3 was supported. The results of the analyses related to this hypothesis indicated that for all three subscales the actions of a group of perpetrators were more upsetting than the actions of a single perpetrator. This issue merits closer examination in future studies. Currently, there is not a lot of research pertaining to the difference between experiencing negative workplace behaviors at the hands of an individual as opposed to at the hands of a group.

To test hypothesis 4 , workplace hostility will predict job satisfaction above and beyond control factors, hierarchical regression was used with job satisfaction as the criterion measure. This study defined job satisfaction as a combination of independent outcome measures related to a participant's intent to leave (i.e., "I probably will be in this job for some time to come," and "I expect to leave for another company within the 
next year"), and desire to continue employment (i.e., "If I have my own way, I will be working for my current organization 5 years from now"). The job satisfaction scale was coded so that higher scores indicated less job satisfaction than lower scores. The coefficient alpha of the job satisfaction measure was .84.

The regression included three steps and five predictor variables. In the first step, the three WHI subscales were entered. In the second step, two measures related to the participants' feelings about their coworkers and supervisors were entered. The feelings about supervisors scale was a combination of items about how participants felt about their supervisors (i.e., "I have a helpful supervisor") and how they perceived their supervisor to feel about them (i.e., "My supervisor is concerned about me"). The coefficient alpha of the feelings about supervisor scale was .85 . The feelings about coworkers scale combined questions about how they felt about their coworkers (i.e., "My coworkers are competent" and "My coworkers are helpful") and how they perceived their coworkers to feel about them (i.e., "My workers are interested in me" and "I have hostile coworkers") and had coefficient alpha reliability of .84. As with the job satisfaction scale, the supervisor and coworker scales were coded so that higher scores indicated less satisfaction with their supervisor and coworkers than lower scores.

The final step of the regression entered job clarity. Job clarity used items related to participants' feeling about their goals and objectives, what people expect of them, and their level of certainty about their authority (i.e., "Are you unsure about what people expect of you?" and "Do clear, planned goals and objectives exist for your job?"). The coefficient alpha for the job clarity scale was .85 . 
The results of this regression indicated that in the first step exclusion significantly predicted workplace hostility. However, in the second step this changed. When the feelings about coworkers and supervisor were entered, the exclusion scale changed to non-significant and both feelings about supervisor and feelings about coworkers were significant. In the final step job clarity significantly enhanced the model, the WHI subscales remained non-significant, and the feelings about coworkers and supervisor remained significant. See Table 5.

This finding is important because it indicates that feelings about other people in the workplace have an effect on an individual's satisfaction. In fact, according to this model, feelings about others are the core factors in predicting job satisfaction. What this model cannot measure and therefore merits closer examination is the relationship between feelings about others and the experience of workplace hostility. With this current data, it is not possible to assess if participants who are indicating that they have negative feelings about others have those feelings due to being mistreated or if they are mistreated due to the negative feelings they have. It is possible that individuals who report having negative feelings about others display those negative feelings in the workplace eliciting poor treatment in response. While conversely, the negative feelings may be developed as a result of perceived or real mistreatment at the hands of others. The issue of cause and effect between hostility and feelings about others is critical to a more complete understanding of the dynamics of workplace aggression.

\section{General Discussion}

The first two studies discussed, the norm pilot study and instrument pilot study, provided the necessary groundwork for the development of the WHI. Prior to the norm 
pilot study, no other study had empirically verified that the behaviors being examined were considered to be norm violations. This is an important component of the harmful workplace behavior field because if the behaviors are generally socially accepted, or even worse expected, then it is difficult to argue that they are deviant behaviors, an implicit component of almost every measure of harmful workplace behaviors.

The instrument study verified that the WHI was comprehensive and did not leave out major harmful behaviors that people report experiencing. When given the chance to provide behaviors other than those included on WHI, participants either indicated that there were no missing behaviors or provided behaviors that were physical in nature, a subset of behaviors intentionally excluded from the WHI. Examined together, the norm pilot study and the instrument pilot study provided support for the development and use of the WHI.

The construct of workplace hostility was developed to fill an existing gap in the literature and to integrate overlapping constructs previously treated as completely distinct. This was examined in the main study. The WHI contained three related subscales. The fact that there were three subscales (as opposed to only one) and they did not align with the scales from which they were originally derived indicates that although workplace hostility is comprehensive it represents more than merely a combination of other constructs.

The relative importance of the exclusion subscale merits closer examination. This subscale was found to be the best predictor of workplace hostility such that the more upset people were with behaviors related to exclusion the more likely they were to 
indicate they were victims of workplace hostility. Additionally, exclusion was, at least initially, a significant predictor of job satisfaction.

These findings support and extend many previous findings in the field of workplace mistreatment. For example, it has been found that employees who experienced persistent workplace aggression were more bothered by the general work environment, had lower levels of job satisfaction and organizational satisfaction, and higher intent to leave the organization when compared to employees who had experienced no aggression or far less frequent aggression [12]. However, this research also did not explore the cause and effect relationship between the work environment and a variety of outcome variables [12]. The direction of causality was assumed. The current study highlights the need to explore this further as it is possible that the people are experiencing hostility due to the negative work environment they have created for themselves (and others) as opposed to the other way around or, even that the two interact to produce the outcome and mutually cause each other.

Another important subscale is interference. Interference was found be especially upsetting when it was experienced by a person and done by a supervisor. This is especially important when considering previous research into power differentials between the target and the perpetrator. It has been indicated that poor treatment by a supervisor can negatively affect many different personal and organizational variables [13] [18]. This finding was supported by this research, however, it was also found that there was a relationship between an individual's feeling about his supervisor and his level of workplace hostility. This is a significant extension on the existing beliefs. It indicates that treatment by a supervisor may be even more important than was 
previously believed. It also implies that feelings about management may be at the root of many judgments made in regard to the workplace. Thus, the key to reducing hostility in the workplace may be in the determining how to mitigate feelings about others in the workplace.

There are numerous practical implications to the current study. The first and most obvious is the potential to use the scale and the subscales to further explore the role that managers/supervisors play in their employee's satisfaction with work. The link between feelings about supervisors and job satisfaction still needs to be fully explored but the potential ramifications of the findings can be applied to numerous workplace settings.

Second, the identification of exclusion as the construct that accounts for the most variance in predicting the occurrence of workplace hostility is an indication that people are particularly upset by others taking actions that makes them feel ostracized and belittled. Knowing this allows managers/supervisors to take preventative steps to ensure that people do not feel excluded. This could presumably be accomplished many different ways, but perhaps the easiest would be one-to-one attention from the manager to the subordinate, assuming the supervisor is not the one doing the excluding.

Finally, the practical implications of having a global scale that can be easily administered and measures whether the work environment is hostile or not is invaluable. The WHI removes the "gray" area in defining a hostile workplace and, if administered to an entire company, could be used to objectively assess whether a specific workplace is hostile or not. 
As with every study, there were some limitations with this study. These limitations do not invalidate the results but are important to mention and address in subsequent studies. First, the data collection method is a potential limitation. However, Internet based sample data collection procedures have compared favorably to conventional samples [24] and within the workplace survey administration method has be found to have little practical impact on the data [25]. With the above in mind, it is still not known exactly what differences exist between a person who would seek out a website about workplace hostility as opposed to someone who passively experiences it. Likewise, it is not known if the gender gap in the respondents is due to an actual gender difference in the experience of workplace hostility or if it can be attributed to some other factor. In subsequent studies, the difference between the current sample and other samples collected in a workplace setting should be compared.

Second, the results of this study are preliminary. The measurement instrument was developed and tested in the same sample. Subsequent studies should be conducted to ensure that the measurement instrument structure and reliability can be replicated.

Third, the current study took into account the perceptions of the target about the perpetrator's intent but did not actually measure the perpetrator's intent. Therefore, targets may have been the victims of unintentional hostility that was perceived as intentional hostility. Although it would be difficult, it would be beneficial to conduct a 360degree assessment where the target's perceptions of intent are measured and compared to the perpetrator's expressed intent and the intent perceived by others in the 
workplace. A 360-degree approach would highlight discrepancies between what is perceived and what is intended. It is possible that they are not the same thing.

Finally, the model needs further exploration. More specifically, the model needs to be fit to additional samples to ensure reliability. Additionally, the cause and effect relationship between workplace hostility and feelings about others needs to be measured in subsequent studies. The relationship appears to be at the root of an individual's job satisfaction but could not be assessed with the current sample.

\section{Conclusions and Implications}

The results of the current study are important and represent a significant advancement in the field of negative workplace behaviors. This is true for several reasons. First, the current study replicated many previous findings, lending overall validity to the field. This is especially noteworthy considering the non-traditional method of data collection. The fact that many of the same issues are present in a self-selected sample as are present in a "normal" workplace sample indicates that, at least for studies of negative workplace behaviors, looking at a self-selected sample yields important and relevant results. Second, the current study discovered a previously overlooked link between feelings about the workplace and the experience of workplace hostility. Further research into this finding will indicate how important this relationship actually is, but have the empirical evidence showing that the causality between the variables needs to be examined is a large step in the right direction. Finally, the development of the WHI represents a collaboration of ideas from many respected constructs that had previously been treated as separate constructs [12] [5] [14] [15] [13] [16] [18] [19]. A previously narrow focus on empirical research within the field has lead to a surplus of broadly 
defined concepts that cover numerous negative workplace behaviors. These concepts are nominally similar, tending to only differ slightly. The WHI is an inclusive scale, representing concepts from numerous negative workplace behaviors thereby creating a global term that includes many of the previous unique and narrowly defined terms. Previously there was an overlap in ideas but not an overlap in terminology. Now, with the $\mathrm{WHI}$, there is a comprehensive and global measure that encompasses the overlap in ideas in previous research. 


\section{References}

[1] Einarsen, H. Hoel, D. Zapf, \& C.L. Cooper (2003). Bullying and Emotional Abuse in the Workplace: International Perspectives in Research and Practice. London: Taylor and Francis.

[2] Fox, S. \& Spector, E. (2005). Counterproductive work behavior: Investigations of actors and targets. Washington, DC: American Psychological Association.

[3] Keashly, L. \& Neuman, J.H. (2004). Bullying in the workplace: Its impact and management. Employee Rights and Employment Policy Journal, 8, 335-373.

[4] Keashly, L. \& Jagatic, K. (2003). By any other name: American perspectives on workplace bullying. In S. Einarsen, H. Hoel, D. Zapf, \& C. Cooper (Eds.) Bullying and Emotional Abuse in the Workplace: International Perspectives in Research and Practice. London: Taylor Francis.

[5] Tepper, B.J. (2000). Consequences of abusive supervision. Academy of Management Journal, 43, 178-190. doi:10.2307/1556375

[6] Zellars, K. L., Tepper, B. J., \& Duffy, M. K. (2002). Abusive supervision and subordinates' organizational citizenship behavior. Journal of Applied Psychology, 87, 1068-1076. doi:10.1037/0021-9010.87.6.1068

[7] Equal Employment Opportunity Commission. (1980). Discrimination because of sex under Title VII of the Civil Rights Act 1964, as amended; adoption of interim interpretative guidelines. Federal Register, 45, 25024-25025.

[8] Schat, A. C. H.. \& Kelloway, E. K., (2005). Workplace Aggression. In J. Barling, E. K. Kelloway, \& M. R. Frone (Eds.) Handbook of Work Stress (pp. 189-218). London: Sage Publications. 
[9] Namie, G. \& Namie, R. (2004). Workplace bullying: How to address America's silent epidemic. Employee Rights and Employment Policy Journal, 8, 335-373.

[10] Neuman, J. H., \& Baron, R. A. (2005). Aggression in the workplace: A social psychological perspective. In S. Fox \& P. E. Spector (Eds.), Counterproductive work behavior: Investigations of actors and targets (pp. 13-40). Washington, DC: American Psychological Association.

[11] Hershcovis, M. S., Turner, N., Barling, J., Inness, M., LeBlanc, M. M., Arnold, K. A., Dupre, K. E., \& Sivanathan, N. (2007). Predicting workplace aggression: A metaanalysis. Journal of Applied Psychology, 92, 228-238.

[12] Neuman, J. H., \& Keashly, L. (2004, April 4). Development of the workplace aggression research questionnaire (WAR-Q): Preliminary data from the workplace stress and aggression project. In R. J. Bennett \& C. D. Crossley (Chairs), Theoretical advancements in the study of anti-social behavior at work. Symposium conducted at the meeting of the Society for Industrial and Organizational Psychology, Chicago, IL.

[13] Duffy, M.K., Ganster, D.C., \& Pagon, M. (2002). Social undermining in the workplace. Academy of Management Journal, 45, 331-351. doi:10.2307/3069350

[14] Robinson, S. L. \& Bennett. R. J., (1995). A typology of deviant workplace behaviors: A multidimensional scaling study. Academy of Management Journal, 38, 555-572. doi:10.2307/256693 
[15] Bennett, R. J., \& Robinson, S. L. (2000). Development of a measure of workplace deviance. Journal of Applied Psychology, 85, 349-360. doi:10.1037/00219010.85.3.349

[16] Cortina, L.M., Magley, V.J., Williams, J.H., \& Langhout, R.D. (2001). Incivility in the workplace: Incidence and impact. Journal of Occupational Health Psychology, 6, 64-80. doi:10.1037/1076-8998.6.1.64

[17] Pearson, C.M., Anderson, L.M., \& Wegner, J.W. (2001). When workers flout convention: A study of workplace incivility. Human Relations, 54, 1387-1419. doi:10.1177/00187267015411001

[18] Donovan, M. A., Drasgow, F., \& Munson, L. J. (1998). The perceptions of fair interpersonal treatment scale: Development and validation of measure of interpersonal treatment in the workplace. Journal of Applied Psychology, 83, 683692. doi:10.1037/0021-9010.83.5.683

[19] Ruehlman, L. S. \& Karoly, P. (1991). With a little flak from my friends: Development and validation of the test of negative social exchange (TENSE). A Journal of Consulting and Clinical Psychology, 3, 97-104. doi:10.1037/1040-3590.3.1.97

[20] Namie, R. \& Namie, G. (2003) The Bully at Work. DoubleDoc Press.

[21] Namie, G. (2001). U.S. Hostile Workplace Survey 2000. Retrieved from Workplace Bullying Institute Web site: http://www.bullyinginstitute.org/res/2000wbti.pdf

[22] Namie, G. (2003). The Workplace Bullying \& Trauma Institute (WBTI) 2003 Report on Abusive Workplaces. Retrieved from Workplace Bullying Institute Web site: http://www.bullyinginstitute.org/res/2003results.pdf 
[23] Namie, G. (1998). WBI 1998 Survey Results. Retrieved from Workplace Bullying Institute Web site: http://www.bullyinginstitute.org/res/niosh99.html

[24] Buchanan, T. and Smith, J. L. (1999). Using the Internet for psychological research: Personality testing on the World Wide Web. British Journal of Psychology, 90, 125-144. doi:10.1348/000712699161189

[25] Church, A. H. (2001). Is there a method to our madness? The impact of data collection methodology on organizational survey results. Personnel Psychology, 54, 937-969. doi:10.1111/j.1744-6570.2001.tb00238.x

[26] Tabachnick, B.G., \& Fidell, L.S. (2001). Using multivariate statistics $\left(4^{\text {th }}\right.$ ed.). Boston: Allyn \& Bacon.

[27] Stevens, J. (2001). Applied multivariate statistics for the social sciences ( $4^{\text {th }}$ ed.). Hillsdale, NJ: Lawrence Erlbaum Associates.

[28] Neuman J. H. \& Baron R. A. (1997). Aggression in the workplace. In R. A. Giacalone and J. Greenberg (eds), Antisocial behavior in organizations (pp. 3767). Thousand Oaks, CA: Sage Publications, Inc.

[29] Berry, C. M., Ones, D. S., and Sackett P.R. (2007). Interpersonal deviance, organizational deviance, and their common correlates: A review and metaanalysis. Journal of Applied Psychology. 92, 410-424. doi:10.1037/00219010.92 .2 .410

[30] Price Spratlen, L. (1995). Interpersonal conflict which includes mistreatment in a university workplace. Violence and Victims, 10, 285-297.

[31] Leymann, H. (1990). Mobbing and psychological terror at workplaces. Violence and Victims, 5, 119-126. 
[32] Glomb, T.M, Steel, P.D.G., \& Arvey, R.D. (2003). Office sneers, snipes, and stab wounds: Antecedents, consequences, and implications of workplace violence and aggression. In R. Lord, R. Klimoski \& R. Kanfer (Eds.), Emotions and Work. San Francisco: Jossey-Bass.

[33] Barling, J. (1996). The prediction, psychological experience and consequences of workplace violence. In G. VandenBos \& E.G. Bulatao (Ed.) Violence on the Job: Identifying Risks and Developing Solutions (pp. 29-49) Washington, DC: American Psychological Association.

[34] O'Leary-Kelly, A. M., Duffy, M. K., \& Griffin, R. W. (2000). Construct confusion in the study of antisocial work behavior. Research in Personnel and Human Resource Management,18, 275-303.

[35] Ferris, D. L., Brown, D. J., Berry, J., \& Lian, H. (2008). The development and validation of the workplace ostracism scale. Journal of Applied Psychology, 93, 1348-1366. doi:10.1037/a0012743

[36] Dalal, S. R. (2005). A meta-analysis of the relationship between organizational citizenship behavior and counterproductive work behavior. Journal of Applied Psychology, 90, 1241-1255. doi:10.1037/0021-9010.90.6.1241 
Table 1.

Major constructs in the field of harmful workplace behaviors

\section{Construct}

Workplace aggression

Neuman \& Baron, 1997 [28]; Schat \& Kelloway, 2005 [8]

Deviant workplace behaviorsinterpersonal deviance

Robinson \& Bennet: 1995 [14]; Berry, Ones, \& Sackett, 2007 [29]

Abusive supervision

Zellars, Tepper, \& Duffy: 2002 [6]: Tepper, 2000 [5]

Social undermining

Duffy, Ganster, \& Pagon, 2002 [13]

Interpersonal conflict

Price Spratlen: 1995 [30]

Mobbing

Leymann: 1990 [31]

Workplace violence

Glomb: Steel: \& Arvey, 2003 [32]; Barling: 1996 [33]

Incivility

Cortina, Magley, Williams, \& Langhout, 2001 [16]; Pearson, Andersson, \& Wegner, 2001 [17] Bullying

Einarsen, Hoel, Keashley, Zapf, \& Cooper, 2003 [1]: Namie \& Namie, 2003 [20]

Antisocial work behavior

O'Leary, Duffy, \& Griffin, 2000 [34]

Workplace ostracism

Ferris, Brown: Berry, \& Lian, 2008 [35]

Counterproductive work behavior

Fox \& Spector, 2004; Dalal, 2005. 
Table 2.

Main Stucly -- Pattern Matrix for the Promax PAF

\begin{tabular}{|c|c|c|c|}
\hline & $\begin{array}{c}\text { Factro } \\
1\end{array}$ & $\begin{array}{c}\text { Factor } \\
2\end{array}$ & $\begin{array}{c}\text { Factre } \\
3\end{array}$ \\
\hline Perpetratorisjopread rumors or gossiped ahout you & $0.78^{*}$ & & \\
\hline Perpetratorisjattempted to turn other employees against you & 0.69 & & \\
\hline Perpetratorisylied to you & 0.63 & & \\
\hline Perpetratorisydid not defend you when people spoke poorly of you & 0.56 & & \\
\hline $\begin{array}{l}\text { Perpetratorisyunneressarily transmitted damaging information to } \\
\text { higher levels in the organization }\end{array}$ & 0.55 & & \\
\hline $\begin{array}{l}\text { Perpetratorisyneld or attended meetings about your work without } \\
\text { your presence }\end{array}$ & 0.46 & & \\
\hline Perpetratorisyohowed favoritism to other employees & 0.45 & & \\
\hline Perpetratorisyinterfered with wour work antivities & 0.45 & & \\
\hline Perpetratorisycefused your requests for assistance & 0.42 & & \\
\hline Perpetratorisjexcluded you from professirnal camraderie & 0.40 & & \\
\hline Perpetratorisytook advantage of you & 0.37 & & \\
\hline Perpetratorisybroke promises heisheithey made to you & 0.37 & & \\
\hline Perpetratorisydeliberately invaded your privacy & 0.35 & & \\
\hline Perpetratoriskgave you the silent treatment & 0.35 & & \\
\hline Perpetratorisyeprimanded you in front of others & & 0.70 & \\
\hline $\begin{array}{l}\text { Perpetratoris;zubjented you to excessively harsh nriticism about } \\
\text { your woxk }\end{array}$ & & 0.66 & \\
\hline Perpetratorisytalked down to you & & 0.64 & \\
\hline Perpetratorisybelittled you or your ideas & & 0.63 & \\
\hline $\begin{array}{l}\text { Perpetratorisydoubted your judgment on a matter over which you } \\
\text { have responsibility }\end{array}$ & & 0.62 & \\
\hline $\begin{array}{l}\text { Perpetratoris soubjected you to negative comments about your } \\
\text { intelligence or competence }\end{array}$ & & 0.52 & \\
\hline Perpetratorishyelled or shouted at you & & $0.47^{*}$ & \\
\hline Perpetratorisygnoxed your contributions & & $0.46^{*}$ & \\
\hline Perpetratoris sprevented you from expressing yourself & & 0.40 & \\
\hline Perpetratorisytook credit for your work ox ideas & & $0.40^{*}$ & \\
\hline Perpetratoriskblamed you for other perples' mistakes & & 0.37 & \\
\hline Perpetratorisjsubjented you to derogatroy name nalling & & & 0.71 \\
\hline Perpetratorisyswore at you in a hostile manner & & & 0.61 \\
\hline Perpetratorisyzidiruled you & & & $0.51^{*}$ \\
\hline Perpetratorisyaughed in your face & & & 0.48 \\
\hline Perpetratorisyout you drwn in front of others & & & $0.43^{*}$ \\
\hline
\end{tabular}

- Cross loading oncurred 
Table 3 .

Main Study - MANOVA Results

\begin{tabular}{|c|c|c|c|c|c|}
\hline Predictor Variable & Wilks' A & $\mathrm{F}$ & DF & $\mathrm{p}$ & $\eta_{1}{ }^{2}$ \\
\hline WH by Type of Perpetrator & 0.88 & 6.19 & $(6,608)$ & 0.00 & 0.06 \\
\hline WH by Individual VS Groups of Perpetrator(s) & 0.86 & 17.74 & $(3,306)$ & 0.00 & 0.14 \\
\hline
\end{tabular}


Table 4.

Main Study - Discriminant Function Analyses Results

\begin{tabular}{|c|c|c|c|c|c|c|}
\hline Predictor Variable & $\begin{array}{l}\text { Correlation } \\
\text { Coefficients with Sig. } \\
\text { Discriminant } \\
\text { Functions } \\
\end{array}$ & $\begin{array}{l}\text { Standardized } \\
\text { Function } \\
\text { Coefficients }\end{array}$ & $A$ & $x^{\prime \prime}$ & DF & p \\
\hline WH by Type of Perpetrator & & & 0.89 & 36.17 & 6 & 0.00 \\
\hline $\begin{array}{l}\text { Exclsuion } \\
\text { Interference } \\
\text { Denigration }\end{array}$ & $\begin{array}{l}0.99 \\
0.63 \\
0.47\end{array}$ & $\begin{array}{r}0.10 \\
1.00 \\
-0.12\end{array}$ & & & & \\
\hline \multicolumn{3}{|c|}{ WH by Individual VS Groups of Perpetrator(s) } & 0.94 & 17.61 & 6 & 0.10 \\
\hline $\begin{array}{l}\text { Exclsuion } \\
\text { Interference } \\
\text { Denigration }\end{array}$ & $\begin{array}{l}0.49 \\
0.99 \\
0.31\end{array}$ & $\begin{array}{r}-0.09 \\
1.08 \\
-0.10 \\
\end{array}$ & & & & \\
\hline
\end{tabular}


Table 5 .

Main Study - Hierarchical Regression Coefficients for Denigration, Exclusion, \& Interference Predicting Job Satistfaction

\begin{tabular}{|c|c|c|c|c|c|c|}
\hline Step & & $R^{3}$ & $1 R^{7}$ & 6 & t & $p$ \\
\hline \multirow[t]{4}{*}{1.00} & & 0.07 & 0.08 & & & 0.000 \\
\hline & Interference & - & - & 0.12 & 1.73 & 0.084 \\
\hline & Exclusion & - & - & 0.24 & 3.11 & 0.002 \\
\hline & Denigration & - & - & -0.08 & -1.12 & 0.265 \\
\hline \multirow[t]{6}{*}{2.00} & & 0.30 & 0.22 & & & 0.000 \\
\hline & Interference & - & - & 0.03 & 0.41 & 0.680 \\
\hline & Exclusion & - & - & 0.13 & 1.94 & 0.054 \\
\hline & Denigration & - & - & -0.02 & -0.37 & 0.714 \\
\hline & Feelings about Supervisors & - & - & 0.36 & 6.71 & 0.000 \\
\hline & Feelings about Coworkers & - & - & 0.22 & 4.19 & 0.000 \\
\hline \multirow[t]{7}{*}{3.00} & & 0.32 & 0.02 & & & 0.003 \\
\hline & Interference & - & - & 0.04 & 0.73 & 0.469 \\
\hline & Exclusion & - & - & 0.11 & 1.66 & 0.099 \\
\hline & Denigration & - & - & -0.02 & -0.39 & 0.701 \\
\hline & Feelings about Supervisors & - & - & 0.31 & 5.37 & 0.000 \\
\hline & Feelings about Coworkers & - & - & 0.20 & 3.70 & 0.000 \\
\hline & Job Glarity & - & - & 0.16 & 2.97 & 0.003 \\
\hline
\end{tabular}

